\title{
Minimally invasive coronary artery bypass as a safe method of surgical revascularization. The step towards hybrid procedures
}

\author{
Jacek Piątek ${ }^{1,2}$, Anna Kędziora ${ }^{1,2}$, Janusz Konstanty-Kalandyk ${ }^{1,2}$, Grzegorz Kiełbasa ${ }^{3}$, Marta Olszewska ${ }^{4}$, \\ Krzysztof Wróbel ${ }^{5}$, Bryan HyoChan Song ${ }^{4}$, Tomasz Darocha ${ }^{1,6}$, Marcin Wróżek ${ }^{4}$, Bogusław Kapelak ${ }^{1,2}$ \\ ${ }^{1}$ Institute of Cardiology, Jagiellonian University Medical College, Krakow, Poland \\ ${ }^{2}$ Department of Cardiovascular Surgery and Transplantology, John Paul II Hospital, Krakow, Poland \\ ${ }^{3}$ First Department of Cardiology, Interventional Electrocardiology and Hypertension, University Hospital, Krakow, Poland \\ ${ }^{4}$ Cardiosurgical Students' Scientific Group, Jagiellonian University Medical College, Krakow, Poland \\ ${ }^{5}$ Department of Cardiac Surgery, Medicover Hospital, Warsaw, Poland \\ ${ }^{6}$ Department of Anesthesiology and Intensive Care, John Paul II Hospital, Krakow, Poland
}

Adv Interv Cardiol 2017; 13, 4 (50): 320-325

DOI: https://doi.org/10.5114/aic.2017.71614

\begin{abstract}
A bstract
Introduction: Coronary artery disease is nowadays responsible for approximately $15 \%$ of hospitalizations in Poland. Minimally invasive coronary artery bypass (MIDCAB) represents an attractive alternative to a sternotomy, and at the same time provides better life quality and facilitates quick rehabilitation.

Aim: To evaluate whether MIDCAB can be performed with similar early and mid-term results as off-pump coronary artery bypass (OPCAB) and therefore can be considered as a safe stage in hybrid revascularization.

Material and methods: In a retrospective cohort study, we analyzed 73 consecutive patients who underwent coronary artery bypass grafting (left internal mammary artery to left anterior descending artery) between 2013 and 2016 in the Department of Cardiovascular Surgery and Transplantology, John Paul II Hospital, Krakow. Thirty-eight (52.1\%) MIDCAB and 35 (47.9\%) OPCAB patients were enrolled.

Results: Short-term results did not significantly differ between groups and similar 30-day mortality was observed (MIDCAB 2.6\% vs. OPCAB $2.9 \%, p=1$ ). The median follow-up period was 21 months. There were no statistical differences in terms of overall survival or cardiac mortality between groups ( $94.7 \%$ vs. $88.6 \%, p=0.42 ; 2.6 \%$ vs. $2.9 \%, p=1$, respectively). The rate of hospitalization due to cardiac causes was similar in both groups $(7.9 \%$ vs. $5.1 \%, p=1)$ and there were no differences in current exacerbation of angina or heart failure, with median NYHA class I and CCS class I in both groups.

Conclusions: Despite higher technical difficulty, MIDCAB procedures can be performed with similar safety results as OPCAB procedures. No differences in terms of mortality, repeat revascularization or recurrent angina are observed.
\end{abstract}

Key words: myocardial revascularization, coronary artery disease, coronary artery bypass grafting surgery, minimally invasive coronary artery bypass, long-term survival, hybrid revascularization.

\section{Introduction}

Coronary artery disease (CAD) is nowadays responsible for approximately $15 \%$ of hospitalizations in Poland. Despite improvement in epidemiology in the last two decades, the early mortality rate (below 65 years old) is still high for these patients, and CAD remains the leading cause of death in developed countries.

According to the European Society of Cardiology (ESC) guidelines, revascularization in multivessel stable
CAD with proximal left anterior descending (LAD) artery involvement is recommended as the best treatment option, and coronary artery bypass grafting (CABG) proves to be beneficial over percutaneous coronary intervention $(\mathrm{PCI})$ in terms of recurrent angina and repeat revascularization [1-3]. The traditional approach for CABG involves a median sternotomy and supplying narrowed arteries with arterial or venous grafts, as it is described elsewhere [4]. In the case of proximal LAD stenosis, the best

\section{Corresponding author:}

Anna Kędziora MD, Department of Cardiovascular Surgery and Transplantology, John Paul II Hospital, 80 Prądnicka St, 31-202 Krakow, Poland, phone: +48 530112 440, e-mail: kdzra.a@gmail.com

Received: 26.08 .2017 , accepted: 10.10 .2017$. 
treatment option includes using left internal mammary artery (LIMA), which has been proved to diminish early postoperative mortality and has excellent both short and long-term results in all age groups, including elder and diabetic patients $[5,6]$. Nevertheless, the traditional CABG procedure, where cardiopulmonary bypass (CPB) is required, may carry an increased risk of postoperative complications in high-risk patients. Therefore, searching for innovative methods of treatment to diminish the risk of surgery and maintain the benefits of LIMA use is warranted. With observed development in both cardiac surgery and invasive cardiology, a promising alternative to combine surgical and percutaneous approaches into a hybrid procedure in order to perform complete revascularization arises. Such a method should provide optimal safety and efficacy of revascularization in the most arduous and complicated cases to both specialties.

Minimally invasive coronary artery bypass (MIDCAB) allows a LIMA to LAD graft to be performed without CPB, and represents an attractive alternative to a sternotomy, as it is proved to provide better life quality and ease quick rehabilitation $[7,8]$. MIDCAB procedures are usually performed through a left anterolateral minithoracotomy with an incision of 5- to 6-cm in length. Then, the pectoralis muscle is displaced bluntly and the ribs are spread with the retractor. Despite higher technical difficulty as the smaller surgical field results in lower visibility, this approach allows one to retain the sternum intact (Figures 1 A, B). Therefore, similar safety and efficacy, and markedly reduced post-operative length of stay, when compared to conventional off-pump CABG (OPCAB), are very promising. Nevertheless, the studies concerning graft patency and mortality reduction after LIMA graft implantation included only patients who were operated on via median sternotomy, and similar results can only be suspected for other approaches.

\section{Aim}

The aim of the study is to evaluate whether MIDCAB can be performed with similar early and mid-term results

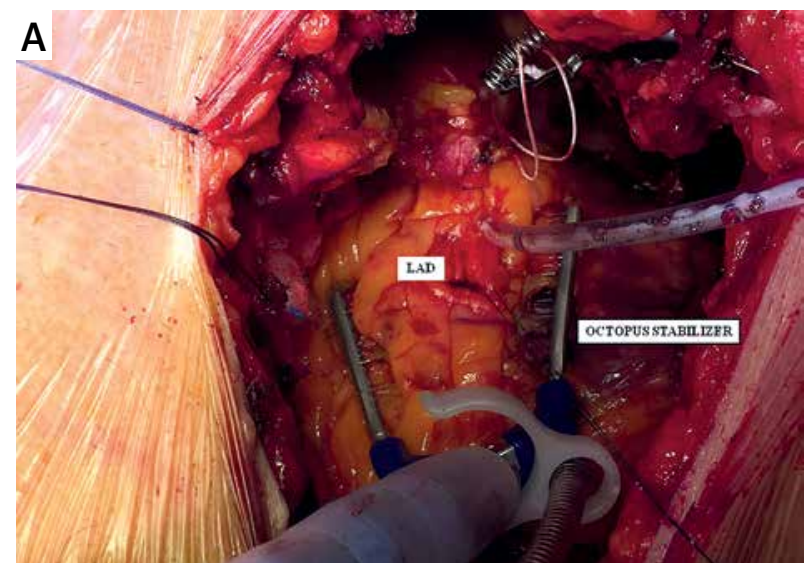

as OPCAB and therefore may be considered as a potential stage in hybrid revascularization.

\section{Material and methods}

In a retrospective cohort study, we analyzed 73 consecutive patients with single-vessel disease who underwent off-pump CABG (LIMA to LAD) between 2013 and 2016 in the Department of Cardiovascular Surgery and Transplantology (38 (52.1\%) MIDCAB vs. 35 (47.9\%) OPCAB). Data were obtained from patient medical records. Follow-up data were obtained as a part of outpatient clinic appointment.

All MIDCAB procedures were performed through a left anterolateral minithoracotomy. After making a 5- to 6-cm skin incision in the fifth intercostal space, the pectoralis muscle was displaced bluntly with minimal division following the muscle fiber orientation. The OPCAB procedures were performed through a median sternotomy. In all of the cases, LIMA was harvested under direct vision, and anastomoses were performed using a vacuum stabilizer, without CPB.

Postoperative complications were assessed, including 30-day mortality, MACCE (defined as any postoperative myocardial infarction (MI), death from cardiac causes and acute stroke), deep wound infection, and need for re-exploration for bleeding and blood products transfusions. Moreover, intensive care unit (ICU) stay and overall hospitalization time were also analyzed.

Follow-up data regarding all-cause and cardiac mortality was obtained from Ministry of the Interior and Administration. The follow-up questionnaire included current CCS and NYHA class, hospitalization due to cardiac causes, requirement for repeated revascularization (PCI or $(A B G), M I$, and stroke.

\section{Statistical analysis}

Statistical analysis was performed using Statistica software, version 12.0. In order to confirm a normal distribution of continuous variables, the Shapiro-Wilk test was used. Results were presented based on the param-

Figure 1. A - Intraoperative view. B - Incision site 14 days after surgery

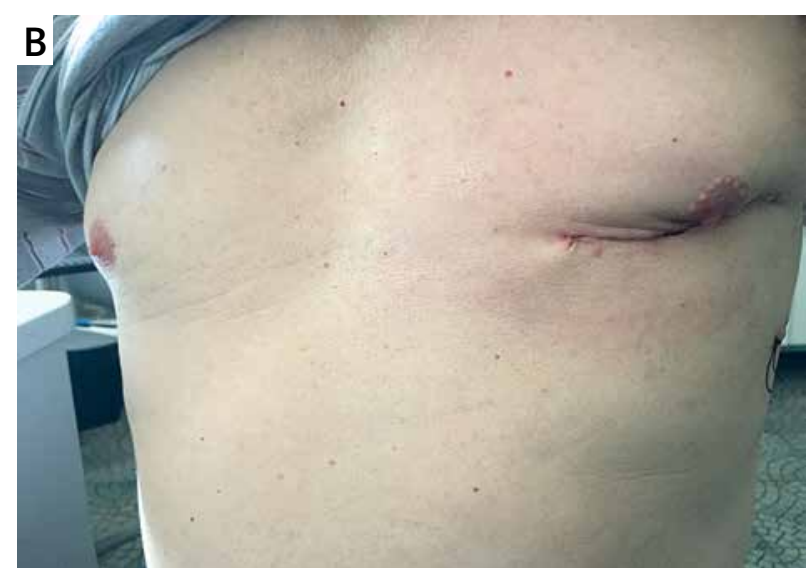


Table I. Baseline characteristics

\begin{tabular}{|c|c|c|c|}
\hline Variable & $\begin{array}{l}\text { MIDCAB } \\
(n=38)\end{array}$ & $\begin{array}{c}\text { OPCAB } \\
(n=35)\end{array}$ & $P$-value \\
\hline Age [years] & $62.92 \pm 9.85$ & $66.43 \pm 9.33$ & 0.12 \\
\hline Male sex, $n(\%)$ & $26(68.42)$ & $23(65.71)$ & 0.81 \\
\hline $\mathrm{BMI}\left[\mathrm{kg} / \mathrm{m}^{2}\right]$ & $27.78 \pm 3.43$ & $28.34 \pm 5.1$ & 0.58 \\
\hline Diabetes, $n(\%)$ & $10(26.32)$ & $13(37.14)$ & 0.32 \\
\hline Hypertension, $n$ (\%) & 35 (92.11) & $35(100)$ & $0.24^{*}$ \\
\hline Hyperlipidemia, $n$ (\%) & $14(36.84)$ & $15(42.86)$ & 0.6 \\
\hline Atrial fibrillation, $n(\%)$ & $2(5.26)$ & $2(5.71)$ & $1^{*}$ \\
\hline COPD, $n(\%)$ & $0(0)$ & $1(2.86)$ & $0.48^{\star}$ \\
\hline CKD, $n(\%)$ & $0(0)$ & $3(8.57)$ & $0.11^{*}$ \\
\hline PAD, $n(\%)$ & $3(7.89)$ & $4(11.43)$ & $0.7^{\star}$ \\
\hline $\operatorname{LVEF}(\%)$ & $55(50-60)$ & $53(48-60)$ & 0.74 \\
\hline EuroSCORE II & $0.73(0.61-0.95)$ & $1.12(0.64-1.42)$ & 0.55 \\
\hline Previous MI, $n(\%)$ & $23(60.53)$ & $21(60)$ & 0.96 \\
\hline Previous PCI, $n$ (\%) & $16(42.11)$ & $17(48.57)$ & 0.58 \\
\hline Previous stroke, $n$ (\%) & $3(7.89)$ & $3(8.57)$ & $1^{*}$ \\
\hline
\end{tabular}

Data shown as mean $\pm S D$ or as median (IQR), or number (percentage). $B M I$ - body mass index, COPD - chronic obstructive pulmonary disease $C K D$ - chronic kidney disease, PAD - peripheral artery disease, LVEF - left ventricle ejection fraction, $\mathrm{MI}$ - myocardial infarction, $\mathrm{PCl}$ - percutaneous coronary intervention. *Fisher's exact test.

Table II. Postoperative complications

\begin{tabular}{lccc} 
Variable & $\begin{array}{c}\text { MIDCAB } \\
(n=38)\end{array}$ & $\begin{array}{c}\text { OPCAB } \\
(n=35)\end{array}$ & P-value \\
\hline $\begin{array}{l}\text { 30-day mortality, } \\
n(\%)\end{array}$ & $1(2.63)$ & $1(2.86)$ & $1^{*}$ \\
\hline $\begin{array}{l}\text { MI, } n(\%) \\
\text { MACCE, } n \text { (\%) }\end{array}$ & $1(2.63)$ & $0(0)$ & $1^{*}$ \\
\hline $\begin{array}{l}\text { Deep wound } \\
\text { infection, } n \text { (\%) }\end{array}$ & $2(5.26)$ & $1(2.86)$ & $1^{*}$ \\
\hline $\begin{array}{l}\text { Re-exploration for } \\
\text { bleeding, } n \text { (\%) }\end{array}$ & $0(0)$ & $2(5.71)$ & $0.23^{*}$ \\
\hline $\begin{array}{l}\text { PRBC transfusions, } \\
n(\%)\end{array}$ & $4(10.53)$ & $10(28.57)$ & 0.05 \\
\hline $\begin{array}{l}\text { FFP transfusions, } \\
n(\%)\end{array}$ & $6(15.79)$ & $3(8.57)$ & $0.48^{*}$ \\
\hline $\begin{array}{l}\text { PLT transfusions, } \\
n(\%)\end{array}$ & $1(2.63)$ & $3(8.57)$ & $0.34^{*}$ \\
\hline $\begin{array}{l}24-h o u r \\
\text { chest tubost-surgery } \\
\text { volume [ml] }\end{array}$ & $495(380-730)$ & $560(400-760)$ & 0.35 \\
\hline $\begin{array}{l}\text { ICU stay [days] } \\
\text { Hospital stay [days] }\end{array}$ & $8(7-9)$ & & 0.11 \\
\hline
\end{tabular}

Data shown as median (IQR), or number (percentage). MI - myocardial infarction, MACCE - major adverse cardiac and cerebrovascular event, PRBC - packed red blood cells, FFP - fresh frozen plasma, PLT - platelets, ICU - intensive care unit. ${ }^{*}$ Fisher's exact test. eters of descriptive statistics, including mean values and its standard deviations, or median values and its quartiles, as appropriate. Categorical variables were presented as percentages. Continuous variables were compared via Student's $t$-test and categorical variables via the $\chi^{2}$ test or Fisher's exact test as appropriate. Kaplan-Meier survival curves and log-rank tests were used in order to compare follow up all-cause and cardiac mortality. A $p$-value less than 0.05 was considered significant.

\section{Results}

Most of the operated patients were male (67.1\%), with a mean age of $64.6 \pm 9.7$ years. Patients included in the study had low perioperative risk (median EuroSCORE II $0.8 \%$ 0.64-1.25) and preserved left ventricular ejection fraction (LVEF) (median 55\% 50-60). The study groups did not differ significantly in terms of baseline characteristics, including the perioperative risk, medical history of cardiovascular diseases, exacerbation of angina, and heart failure assessed on admission, and other comorbidities (Table I).

The median procedure time was significantly lower in the MIDCAB group (177.5 vs. 120 min, $p=0.04$ ). Multivariate stepwise regression and subgroup analysis showed that none of the preoperative parameters influenced the MIDCAB procedure time. However, older age and higher EuroSCORE II prolonged OPCAB surgery $(p<0.01)$.

Short-term results did not significantly differ between groups and similar 30-day mortality was observed (2.6\% vs. $2.9 \%, p=1$ ). In the MIDCAB group, one of the patients had sudden cardiac arrest, which occurred after hospital discharge. The patient, however, had a high perioperative risk due to impaired LVEF ( $23 \%$ assessed by cardiac MRI). In the OPCAB group, sepsis and sternal dehiscence treated with a vacuum-assisted closure device were observed in one of the patients and the course was complicated with fatal right ventricle rupture.

Within the early postoperative period, only 1 case of $\mathrm{MI}$ occurred in the MIDCAB group and early graft occlusion was diagnosed without a fatal outcome. Deep wound infection was observed in 2 individuals who underwent OPCAB. Two cases of re-exploration for bleeding were reported in the MIDCAB group. One was due to pleural hematoma and the other due to LIMA graft bleeding. In spite of no differences in the chest tube drainage volume, packed red blood cells (PRBC) were transfused more often in the OPCAB group $(p=0.05)$ (Table II).

The only factor influencing the incidence of postoperative complications in the whole study group was chronic kidney disease (CKD) ( $p=0.007)$.

Follow-up data regarding all-cause and cardiac mortality were obtained from all of the patients. The median follow-up period was 21 months. There were no significant differences in terms of overall survival or cardiac mortality between groups (Figures 2, 3). 


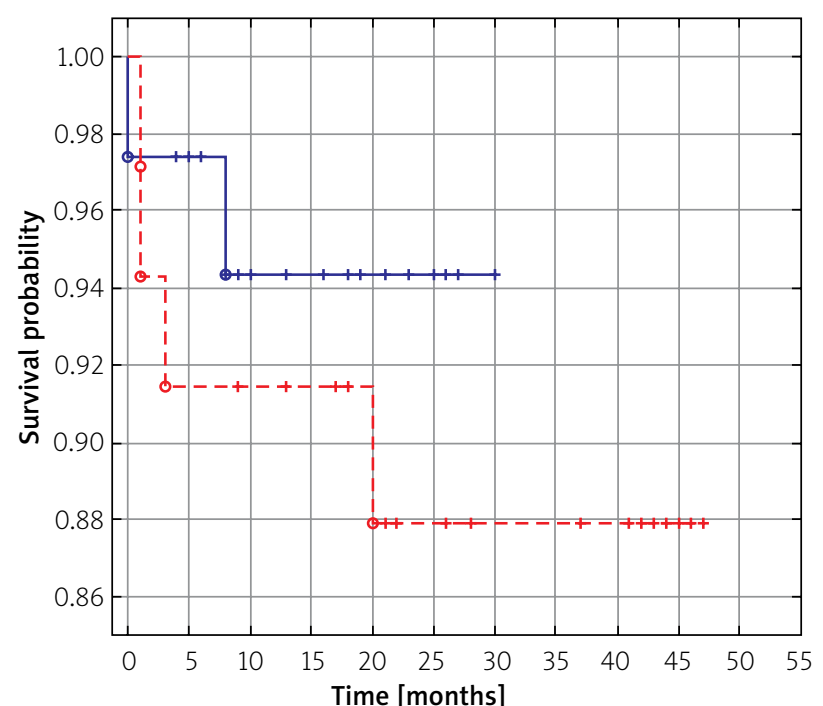

Number at risk

$\begin{array}{lllllllllll}\text { MIDCAB } 37 & 32 & 27 & 22 & 15 & 8 & 2 & 0 & 0 & 0 & 0\end{array}$ $\begin{array}{llllllllllll}O P C A B & 35 & 32 & 30 & 28 & 23 & 17 & 15 & 15 & 10 & 3 & 0\end{array}$

Figure 2. Survival probability. Log-rank test $p>0.05$

The rate of hospitalization due to cardiac causes was similar in both groups and there were no differences in current exacerbation of angina or heart failure, with median NYHA class I and CCS class I in both groups (Table III).

\section{Discussion}

Minimally invasive approaches have been of interest to many surgeons recently as general advantages include quick rehabilitation and superior cosmetic results [9]. Low perioperative mortality comparable to conventional off-pump technique has been previously reported [10], which is consistent with the study findings. Nevertheless, the most appealing benefits consist of lowering the incidence of expensive complications, such as deep wound infection and sternal dehiscence [9], which in the study were observed only in the OPCAB group. Aside from newly instituted hemodialysis, these complications have been determined to highly increase the surgery cost, up to $\$ 56,003$ in the American study and $€ 36.261$ in the European one $[11,12]$. In contrast, surgical site infections after minimally invasive surgery are usually superficial and occur mostly in obese and female patients when the pressure placed on the wound edges by the retractor leads to tissue necrosis $[13,14]$.

Furthermore, prospective observation of graft patency in patients undergoing multi-vessel revascularization through a minimally invasive approach revealed significantly lower rates for grafts other than LIMA to LAD [15]. This leads to the hypothesis that a hybrid approach combining minimally invasive LIMA to LAD graft with $\mathrm{PCI}$ to other diseased arteries constitutes one area where

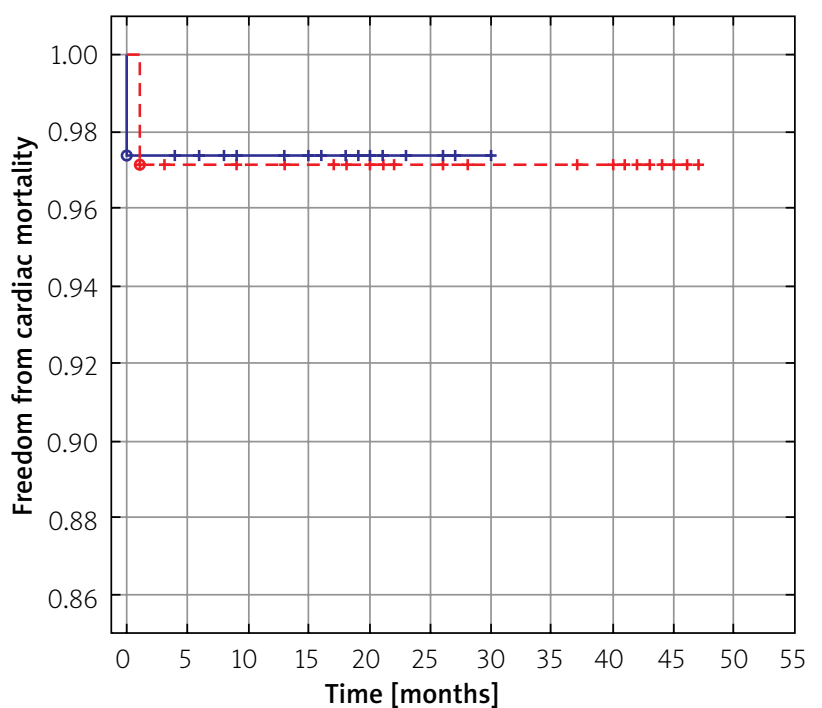

Number at risk

$\begin{array}{lllllllllll}\text { MIDCAB } 37 & 32 & 27 & 22 & 15 & 8 & 2 & 0 & 0 & 0 & 0\end{array}$

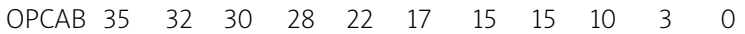

$$
\text { - MIDCAB - - OPCAB }
$$

Figure 3. Freedom from cardiac mortality. Log-rank test $p>0.05$

MIDCAB procedures may find their greatest technical approachability, best patency results, and potentially highest institutional applicability. The MIDCAB is an especially attractive alternative for high-risk patients who would be disqualified from conventional CABG surgery and in whom complete revascularization using $\mathrm{PCI}$ might be technically difficult. It is a well stated fact that multivessel CAD itself is associated with lower rates of successful percutaneous revascularization, an increased number of complications and consequently with worse in-hospital and long-term outcomes [16]. Moreover, the risk seems to rise together with the atherosclerosis progression and calcification, especially in the scope of the left main coronary artery [17].

Nevertheless, MIDCAB procedures have additional relative contraindications, such as pulmonary disorders,

Table III. Follow-up data

\begin{tabular}{lccc} 
Variable & $\begin{array}{c}\text { MIDCAB } \\
(n=38)\end{array}$ & $\begin{array}{c}\text { OPCAB } \\
(n=35)\end{array}$ & $P$-value \\
\hline All-cause mortality, $n(\%)$ & $2(5.26)$ & $4(11.43)$ & $0.42^{\star}$ \\
\hline Cardiac mortality, $n(\%)$ & $1(2.63)$ & $1(2.86)$ & $1^{\star}$ \\
\hline $\begin{array}{l}\text { Hospitalization due to } \\
\text { cardiac causes, } n(\%)\end{array}$ & $3(7.89)$ & $2(5.71)$ & $1^{\star}$ \\
\hline MI, $n(\%)$ & $0(0)$ & $0(0)$ & $1^{\star}$ \\
\hline PCI, $n(\%)$ & $1(3.13)$ & $0(0)$ & $1^{\star}$ \\
\hline Cardiac surgery, $n(\%)$ & $0(0)$ & $0(0)$ & $1^{\star}$ \\
\hline Stroke, $n(\%)$ & $0(0)$ & $0(0)$ & $1^{\star}$
\end{tabular}

Data shown as number (percentage). MI - myocardial infarction, $\mathrm{PCl}$ - percuta neous coronary intervention. ${ }^{*}$ Fisher's exact test. 
as they require intraoperative single-lung ventilation. Although most studies do not report prolonged mechanical ventilation after MIDCAB and in some centers extubation in the operating room is routinely performed [18], in the randomized STET trial significantly worse lung function at discharge was observed in the minimally invasive approach group [19]. However, in our center patients are usually reintubated after surgery and the endotracheal tube is changed to a single-lumen tube. Next, mechanical ventilation is implemented following the same protocol as for the OPCAB procedure. This resulted in no differences observed for the ICU stay and therefore the overall hospitalization time.

However, despite all the advantages, the minimally invasive approach encounters technical difficulties that require highly trained surgical skills. Re-exploration for bleeding is therefore more commonly reported after MIDCAB in most of the studies [9, 13, 19]. Furthermore, although immediate and 6-month patency rates assessed by angiography do not decline below $94 \%$ and are similar to those observed after on-pump CABG, the safety of the minimally invasive procedure, especially in terms of non-inferior long-term graft patency, remains unclear [20-22]. The present study is one of the first to describe the follow-up data in patients after minimally invasive surgical revascularization. Consistent with other reports, the study presented excellent outcomes with low cardiac mortality and repeat revascularization rate [23, 24]. Moreover, the results were comparable to those observed for the OPCAB cohort with similar perioperative risk.

The major consideration regarding the study is the small sample size coming from single-center experience. Moreover, since minimally invasive revascularization has been recently introduced in our center as a method of choice in eligible patients with single-vessel LAD disease, a limited group of patients with limited follow-up data was available. Although higher risk assessed by the EuroSCORE II was not an exclusion criterion and patients were analyzed consecutively, it is worth noting that the cohort presented low estimated periprocedural risk and therefore conclusions regarding more complex cases should be drawn with caution, especially in terms of considering MIDCAB as a stage in hybrid revascularization in high-risk patients with multivessel disease, when the expected complication rate would be higher. The study results evidence only that MIDCAB procedures can be performed with similar results as OPCAB; however, no direct conclusions proving the safety and efficacy of hybrid complete revascularization combining MIDCAB LIMA : LAD and PCI with other diseased arteries may be drawn. Further prospective study to investigate this approach is warranted.

\section{Conclusions}

Despite higher technical difficulty, MIDCAB procedures can be performed with similar safety as OPCAB procedures. No differences in terms of mid-term mortality, repeat revascularization or recurrent angina are observed. Nevertheless, the actual long-term graft patency in this technique is still to be determined.

\section{Conflict of interest}

The authors declare no conflict of interest.

\section{References}

1. Windecker S, Kolh P, Alfonso F, et al. 2014 ESC/EACTS Guidelines on myocardial revascularization. Eur Heart J 2014; 35: 2541-619.

2. Kapoor JR, Gienger AL, Ardehali R, et al. Isolated disease of the proximal left anterior descending artery comparing the effectiveness of percutaneous coronary interventions and coronary artery bypass surgery. JACC Cardiovasc Interv 2008; 1: 483-91.

3. Aziz O, Rao C, Panesar SS, et al. Meta-analysis of minimally invasive internal thoracic artery bypass vs. percutaneous revascularisation for isolated lesions of the left anterior descending artery. BMJ 2007; 334: 617.

4. Şaşkın H, Düzyol Ç, Aksoy R, et al. Do preoperative C-reactive protein and mean platelet volume levels predict development of postoperative atrial fibrillation in patients undergoing isolated coronary artery bypass grafting? Adv Interv Cardiol 2016; 12: 156-63.

5. Arif R, Farag M, Gertner V, et al. Female gender and differences in outcome after isolated coronary artery bypass graft surgery: does age play a role? PLoS One 2016; 11: e0145371.

6. Szychta W, Majstrak F, Opolski G, et al. Blood glucose concentration for predicting poor outcomes in patients with and without impaired glucose metabolism undergoing off-pump coronary artery bypass surgery - long-term observational study. Adv Interv Cardiol 2016; 12: 238-46.

7. Wray J, Al-Ruzzeh S, Mazrani W, et al. Quality of life and coping following minimally invasive direct coronary artery bypass (MIDCAB) surgery. Qual Life Res; 13: 915-24.

8. Head SJ, Borgermann J, Osnabrugge RL, et al. Coronary artery bypass grafting: Part 2: optimizing outcomes and future prospects. Eur Heart J 2013; 34: 2873-86.

9. Balaguer JM, Umakanthan R, Leacche $M$, et al. Minimally invasive cardiac surgery. Curr Probl Surg 2012; 49: 529-49.

10. Gummert JF, Funkat A, Krian A. Cardiac surgery in Germany during 2004: a report on behalf of the German Society for Thoracic and Cardiovascular Surgery. J Thorac Cardiovasc Surg 2005; 53: 391-9.

11. LaPar DJ, Crosby IK, Rich JB, et al. A contemporary cost analysis of postoperative morbidity after coronary artery bypass grafting with and without concomitant aortic valve replacement to improve patient quality and cost-effective care. Ann Thorac Surg 2013; 96: 1621-7.

12. Graf K, Ott E, Vonberg RP, et al. Economic aspects of deep sternal wound infections. Eur J Cardiothorac Surg 2010; 37: 893-6.

13. Lapierre H, Chan V, Sohmer B, et al. Minimally invasive coronary artery bypass grafting via a small thoracotomy versus off-pump: a case-matched study. Eur J Cardiothorac Surg 2011; 40: 804-10.

14. Reddy RC. Minimally invasive direct coronary artery bypass: technical considerations. Semin Thorac Cardiovasc Surg 2011; 23: 216-9.

15. Ruel M, Shariff MA, Lapierre H. Results of the minimally invasive coronary artery bypass grafting angiographic patency study. J Thorac Cardiovasc Surg 2014; 147: 203-8. 
16. Gąsior P, Desperak P, Gierlaszyńska K, et al. Percutaneous coronary intervention in treatment of multivessel coronary artery disease in patients with non-ST-segment elevation acute coronary syndrome. Postep Kardiol Interw 2013; 9: 136-45.

17. Mencel G, Kowalczyk J, Swierad M, et al. Ostial stenosis of the left main coronary artery as the result of the previous percutaneous coronary intervention on the left coronary artery. Postep Kardiol Interw 2013; 9: 317-20.

18. Bainbridge D, Cheng DC. Minimally invasive direct coronary artery bypass and off-pump coronary artery bypass surgery: anesthetic considerations. Anesthesiol Clin 2008; 26: 437-552.

19. Rogers CA, Pike K, Angelini GD, et al. An open randomized controlled trial of median sternotomy versus anterolateral left thoracotomy on morbidity and health care resource use in patients having off-pump coronary artery bypass surgery: the Sternotomy Versus Thoracotomy (STET) trial. J Thorac Cardiovasc Surg 2013; 146: 306-16.

20. Ruel M, Shariff MA, Lapierre $H$. Results of the minimally invasive coronary artery bypass grafting angiographic patency study. J Thorac Cardiovasc Surg 2014; 147: 203-8.

21. Mack MI, Magovern JA, Acuff TA, et al. Results of graft patency by immediate angiography in minimally invasive coronary artery surgery. Ann Thorac Surg 1999; 68: 383-90.

22. Kettering K, Dapunt O, Baer FM. Minimally invasive direct coronary artery bypass grafting: a systematic review. J Cardiovasc Surg 2004; 45: 255-64.

23. Holzhey DM, Jacobs S, Mochalski M, et al. Seven-year follow-up after minimally invasive direct coronary artery bypass: experience with more than 1300 patients. Ann Thorac Surg 2007; 83: 108-14.

24. Pande S, Agarwal SK, Gupta D, et al. Early and mid-term results of minimally invasive coronary artery bypass grafting. Indian Heart J 2014; 66: 193-6. 